\title{
TECNOLOGIAS ASSISTIVAS E INCLUSÃO ESCOLAR: CONTRIBUIÇÕES DA TERAPIA OCUPACIONAL PARA A FORMAÇÃO DE PROFESSORES DO ATENDIMENTO EDUCACIONAL ESPECIALIZADO (AEE) EM BELÉM (PA)
}

\author{
Samantha Hanna Seabra Castilho Simões ${ }^{1}$ \\ Talita Silva Sousa ${ }^{2}$ \\ Débora Ribeiro da Silva Campos Folha ${ }^{3}$
}

\begin{abstract}
Resumo
O presente estudo objetivou verificar possibilidades de contribuição terapêutica ocupacional na formação de professores no que concerne à utilização de Tecnologia Assistiva junto a alunos com deficiência. Para compreender a Educação Inclusiva, buscou-se fundamentação teórica em autores como Galvão, Martins, Pelosi, Cavalcante, Lima, Frias e Menezes. Os participantes da pesquisa foram professores das salas de recursos multifuncionais das escolas municipais de Belém/PA. A metodologia consistiu em uma abordagem qualitativa e a coleta de dados, realizada em três momentos: aplicação de um questionário inicial, para identificar as principais demandas a serem contempladas na formação posteriormente proposta; a execução das formações, totalizando quatro momentos ministrados por profissionais e acadêmicos de Terapia Ocupacional sobre Tecnologia Assistiva; aplicação de um questionário final. Emergiram da análise dos dados as categorias: concepções dos professores acerca da Tecnologia Assistiva; benefícios da prática multiprofissional para a formação dos professores; Terapia Ocupacional x Inclusão Escolar. Os resultados encontrados apontam para a necessidade da formação continuada, não só do professor, mas da equipe profissional atuante no contexto inclusivo. Além disso, vale ressaltar a relevância do terapeuta ocupacional como profissional com potencial de auxiliar nesse processo, otimizando a interação, a funcionalidade e as habilidades do indivíduo com deficiência. As formações realizadas permitiram a sensibilização dos professores quanto às peculiaridades e individualidades dos alunos do Atendimento Educacional Especializado, o aprimoramento das práticas e abordagens pedagógicas, a otimização da relação alunoprofessor, bem como uma maior compreensão acerca das teorias e caminhos para a prática da utilização da Tecnologia Assistiva.
\end{abstract}

Palavras-chave: Inclusão Escolar. Tecnologia Assistiva. Terapia Ocupacional.

\section{ASSISTIVE TECHNOLOGIES AND SCHOOL INCLUSION: OCCUPATIONAL THERAPY CONTRIBUTIONS FOR TEACHER EDUCATION FROM THE SPECIALIZED EDUCATIONAL SERVICE (SES) IN BELÉM (PA)}

\begin{abstract}
The present study aimed to verify the possible contributions for Occupational Therapy in teacher training regarding the use of Assistive Technology with students with disabilities. To understand the Inclusive Education, we sought theoretical foundation in authors like Galvão, Martins, Pelosi, Cavalcante, Lima, Frias and Menezes. The participants of this research were teachers of multi-functional resources room of public schools in Belém/PA. The methodology consists of a qualitative approach and data collection, executed in three stages: application of an initial questionnaire to identify the main requirements to be addressed in a later training; the implementation of training that totalizes four parts of discussion on topics related to Assistive Technology given by professionals and academics of Occupational Therapy; and application of a final questionnaire. From the data analysis the following categories emerged: teachers' conceptions about the Assistive Technology; the benefits of multidisciplinary practice for Teacher Training; Occupational Therapy $\mathrm{X}$ School Inclusion. The results point to the need for continued education, not only for the teacher, but for

\footnotetext{
${ }^{1}$ Terapeuta Ocupacional. Vinculação institucional: Universidade do Estado do Pará. E-mail: samantha_castilho92@hotmail.com

${ }^{2}$ Terapeuta Ocupacional. Vinculação institucional: Universidade do Estado do Pará. E-mail: talita-sousa1@ @otmail.com ${ }^{3}$ Mestre em Educação pela Universidade Federal do Pará na Linha de Educação: Currículo, Epistemologia e História. Vinculação institucional: Docente do curso de Terapia Ocupacional na Universidade do Estado do Pará. E-mail: todeboracampos@gmail.com
} 
the staff that works inclusion setting. Moreover, it is important to mention the potential of occupational therapist to assist in this process, optimizing the interaction, functionality and abilities of the individual with disabilities. The performed trainings allowed the teacher's sensitization for the peculiarities and individualities of the specialized educational service's students, the improvement of practices and pedagogical approaches, the optimization of the student-teacher relationship as well as a greater understanding of the theories and ways to practice use of Assistive Technology.

Keywords: School Inclusion. Assistive Technology. Occupational Therapy.

\section{Introdução}

O processo de Inclusão Escolar atualmente é um dos temas mais discutidos no campo da educação em todo o mundo. O direito à educação é direito de toda criança, adolescente ou adulto, independente das diferentes necessidades que possam apresentar e das realidades nas quais se encontram. A Constituição ratifica que todos são iguais perante a lei, não havendo nenhuma distinção. Portanto, a Educação Inclusiva parte dessa premissa, pois defende uma reestruturação da cultura, da prática e das políticas vivenciadas nas escolas de modo que estas respondam à diversidade de alunos (ALVES DE OLIVEIRA et al., 2011).

Esse processo de reforma e reestruturação das escolas como um todo é um desafio à instituição escola, visto que a Inclusão Escolar envolve desde a superação das barreiras arquitetônicas até, e principalmente, a superação das barreiras atitudinais, das práticas pedagógicas, bem como, reivindica-se uma mudança nas perspectivas de professores, dos alunos e da comunidade como um todo (MARTINS, 2006; FRIAS; MENEZES, s/d; GALVÃO FILHO; MIRANDA, 2012).

Para atender as demandas dos alunos com deficiência, surge, em 2007, a Política Nacional de Educação Especial na perspectiva da Educação Inclusiva, a qual garante o acesso desses alunos a escolas regulares, bem como o Atendimento Educacional Especializado (AEE), que tem como uma de suas estratégias as Salas de Recursos Multifuncionais (SRM), com equipamentos e recursos facilitadores do aprendizado, no contra turno do ensino regular (BRASIL, 2007).

É nas salas de recursos multifuncionais que o aluno terá a possibilidade de aprimorar o que conseguiu aprender na sala de aula regular, onde também desenvolve seu potencial de socialização e onde tem a possibilidade de compensar eventuais déficits de aprendizagem e de conhecimentos que não conseguiu apreender apenas frequentando a sala de aula regular. Portanto, o AEE não funciona como substitutivo do ensino regular, mas sim complementar a este (BRASIL, 2007). 
Nesse sentido, observa-se a importância da utilização de diversos recursos no contexto do AEE, dentre estes, a inserção da Tecnologia Assistiva ${ }^{4}$ (TA), a qual se encontra dentro do campo de conhecimento e atuação do terapeuta ocupacional, profissional que enfatiza em sua prática o envolvimento dos seres humanos em ocupações cotidianas e significativas para eles (AOTA, 2008).

É importante ressaltar que os recursos de Tecnologia Assistiva constituem-se como mediadores e potencializadores da interação social da pessoa com deficiência no mundo. Nesse sentido, a TA pode ser concebida como um privilegiado instrumento catalisador e estimulador na construção de novos caminhos e possibilidades para o aprendizado e desenvolvimento dos que apresentam algum tipo de deficiência, pois disponibiliza recursos para o "empoderamento" dessa pessoa, permitindo que possa interagir, relacionar-se e competir em seu meio com ferramentas (GALVÃO, 2009).

No que se refere à falta de conhecimento dos professores sobre a utilização dos recursos de Tecnologia Assistiva, infere-se que esta dificuldade, pode refletir a existência de um possível déficit na formação destes profissionais. Sobre isso, é necessário e urgente, que os sistemas de ensino se organizem para que além de assegurar essas matrículas, assegurem também a permanência de todos os alunos, o desenvolvimento de suas potencialidades e aprendizagem sem perder de vista a intencionalidade pedagógica e a qualidade do ensino (FRIAS; MENEZES, s.d.).

Nesse contexto, o presente estudo traz como tema central possibilidades de contribuição do terapeuta ocupacional junto a professores de SRM no contexto da utilização de dispositivos de TA. O interesse pelo tema surgiu a partir de uma oportunidade oferecida pelo Núcleo de Desenvolvimento em Tecnologia Assistiva e Acessibilidade (NEDETA), estágio não obrigatório, através da execução do projeto intitulado "Levantamento das Necessidades de Recursos de Tecnologia Assistiva nas Escolas Inclusivas Municipais de Belém-PA”, onde se pôde observar que havia nas escolas uma gama interessante de recursos de Tecnologia Assistiva. No entanto, segundo relato dos professores dessas instituições, os recursos não eram utilizados no processo de ensinoaprendizagem dos alunos por falta de conhecimento dos professores no que se referia à utilização de tais recursos.

\footnotetext{
${ }^{4}$ A Tecnologia Assistiva, segundo Bersch e Schirmer (2005), é uma área do conhecimento que se propõe a promover ou ampliar habilidades em pessoas com privações funcionais, em decorrência da deficiência, além de ser composta por recursos e serviços, sendo estes últimos destinados a avaliar, prescrever e orientar a utilização da TA, visando maior independência funcional da pessoa com deficiência na atividade de seu interesse.
} 


\section{Metodologia}

O presente artigo surgiu a partir da pesquisa referente ao Trabalho de Conclusão Final do Curso de Terapia Ocupacional da Universidade do Estado do Pará (UEPA), apresentando um caráter qualitativo.

Teixeira (2009, p.137) versa acerca da pesquisa qualitativa, na qual o pesquisador "procura reduzir a distância entre a teoria e os dados, entre o contexto e a ação, usando a lógica da análise fenomenológica, isto é, da compreensão dos fenômenos pela sua descrição e interpretação".

Enquadraram-se enquanto sujeitos da pesquisa, os professores atuantes nas SRM de escolas pertencentes à rede municipal de ensino de Belém. O Centro de Referência de Inclusão Educacional (CRIE) Gabriel Lima Mendes disponibilizou uma listagem atualizada das escolas que possuem essas salas, as quais totalizam 33 escolas.

Os critérios de inclusão da pesquisa determinavam aptos a participar desta todo professor de SRM das escolas da rede municipal de Belém e que aceitassem participar da mesma, assinando o Termo de Consentimento Livre e Esclarecido (TCLE). Aos critérios de exclusão, que determinavam a exclusão da pesquisa todo profissional que não atendesse aos critérios de inclusão, abriu-se exceção para dois profissionais do CRIE que ao serem informados sobre a segunda etapa da pesquisa-formação para os professores, interessaram-se em participar da mesma. A inserção desses indivíduos no momento das formações foi uma solicitação do CRIE às pesquisadoras.

Os sujeitos participantes foram abordados segundo os preceitos da Declaração de Helsinque e do Código de Nuremberg, respeitadas as normas de pesquisa envolvendo seres humanos (CNS n. 466/2012) do Conselho Nacional de Saúde, onde se desenvolveu o trabalho conforme as exigências para as pesquisas com seres humanos, tendo sido aprovada pelo Comitê de Ética em Pesquisa com seres humanos, sob o CAEE 23277613.7.0000.5174. Para a pesquisa, optouse por identificar os indivíduos por números.

A pesquisa foi realizada em duas etapas. A primeira consistiu na coleta de dados dos participantes, com o objetivo de identificar o perfil dos professores das SRM das escolas municipais de Belém, bem como possibilitar o planejamento dos temas a serem abordados na formação de acordo com as principais demandas visualizadas no primeiro momento.

Com esses dados em mãos, elaboraram-se os módulos que viriam a compor as formações, segunda etapa da pesquisa. Nesta fase foi construído cronograma com os dias e horários das formações e estabelecido os conteúdos que seriam abordados em cada módulo assim como o local onde seriam executadas as formações previamente. 
Posteriormente, foram contatados os profissionais terapeutas ocupacionais que atuavam ativamente nos temas escolhidos para ministrar os módulos das formações e realizado o contato com os professores para divulgação do cronograma e dos conteúdos que seriam abordados nas formações.

Inicialmente objetivava-se desenvolver a pesquisa com todos os professores atuantes nas SRM das escolas indicadas, porém devido dificuldade de contatar esses professores, associada à indisponibilidade e incompatibilidades de horário destes, não foi possível desenvolver conforme o que se tinha proposto. Dentre esses professores, uma amostra de 21 aceitou participar da primeira etapa da coleta de dados da pesquisa.

O local da coleta dos dados da primeira etapa da pesquisa seria nas próprias instituições onde esses professores trabalhavam, porém, devido à dificuldade de acesso direto a essas escolas, a localização longínqua, mudou-se a estratégia e o local de obtenção da coleta aconteceu durante uma reunião promovida pelo CRIE junto a este público, cuja oportunidade foi cedida pelo próprio centro.

Quanto à realização da formação propriamente dita, definiu-se como tema geral a Tecnologia Assistiva no Processo de Inclusão Escolar. Esta temática foi subdividida de modo didático, onde aconteceram quatro módulos cujos temas foram: "Tecnologia Assistiva como recurso para a promoção de práticas inclusivas", "Comunicação Alternativa e Aumentativa", "Recursos de Tecnologia Assistiva: estratégias para efetivação da Inclusão Escolar" e "Oficina de construção de recurso de TA de baixo custo".

Em relação à segunda etapa, participaram das formações propostas apenas 11 professores e outros dois profissionais, um com a função de orientar os professores no processo de Inclusão Escolar, e o outro profissional realizava orientações com as famílias dos alunos com deficiência, ambos funcionários efetivos do CRIE. O número de questionários preenchidos utilizados para análise dos dados desta etapa foi 10, sendo 8 de professores das SRM e 2 de profissionais do CRIE atuantes na perspectiva do AEE.

Vale ressaltar que todos os professores que preencheram o primeiro questionário se comprometeram em participar da segunda etapa da pesquisa que consistiu na formação. Porém, como apontado anteriormente, apenas 11 professores participaram desta última.

Após a execução dos módulos, aplicou-se o segundo questionário aos participantes das formações, a partir do qual se realizou uma análise as respostas dos professores quanto ao conteúdo assimilado e ao processo das formações. 
As falas dos sujeitos de pesquisa foram tratadas qualitativamente através do método de análise do conteúdo. Segundo Bardin (2014), este método consiste na transformação dos dados brutos, possibilitando uma representação do conteúdo expresso pelo sujeito de pesquisa.

A partir da análise das considerações trazidas pelos professores através do instrumento proposto pelas pesquisadoras, foi realizada fundamentação com autores relevantes para as temáticas abordadas, bem como feitas análises relacionando os campos prático e teórico.

Para a realização desta análise estabeleceram-se três etapas: o recorte, a enumeração e a classificação e agregação dos dados. A regra de enumeração utilizada para codificação dos dados foi com base na frequência. A categorização dos dados, através da classificação, organiza os elementos em categorias, permite a investigação da individualidade de cada sujeito, e ao mesmo tempo, os pontos compartilhados entre os participantes da amostra, permitindo a realização de agrupamentos (BARDIN, 2014).

\section{Resultados e discussão}

Os resultados foram obtidos através das respostas de um questionário com perguntas abertas, aplicados após as formações, que objetivou avaliar dois aspectos: Seção I- Quanto ao conteúdo assimilado; Seção II- Quanto ao processo das formações. Este instrumento possibilitou a construção das seguintes categorias de análise.

Elaborou-se uma categoria referente à compreensão dos conceitos, abordados nas formações, pelos professores, denominada "Concepções acerca da Tecnologia Assistiva". Além desta, foram construídas duas categorias de análises relacionadas à visão dos professores quanto ao processo de inclusão: "Benefícios da Prática Multiprofissional para a formação dos professores"; “Terapia Ocupacional x Inclusão Escolar".

Assim, este item apresenta, em forma de categorias e subcategorias, as respostas dos professores, obtidas a partir do questionário final. As respostas foram classificadas de acordo com a pergunta em que se localizavam e ao conteúdo da resposta. Realiza-se também, uma discussão mais aprofundada acerca de cada categoria, fundamentada nas falas e em referenciais teóricos pertinentes.

Nomeou-se a primeira categoria como "Concepções acerca da Tecnologia Assistiva”. Nela, encontram-se as respostas dos professores relacionadas à sua percepção quanto à Tecnologia Assistiva em diversas esferas, tais como conceito, benefícios gerais, benefícios para pessoa com deficiência, no contexto da Educação Inclusiva, dentre outras. 
Para dar conta dessa categoria, o primeiro momento da formação foi destinado à introdução de conceitos e classificações da Tecnologia Assistiva, o que proporcionou, aos professores, a visualização das diversas áreas em que a mesma pode estar inserida.

A formação contemplou como abordagens da TA: auxílios para Atividades de Vida Diária; recursos para Atividades Instrumentais de Vida Diária; Comunicação Alternativa e Ampliada, recursos de acessibilidade ao computador, sistemas de controle do ambiente, projetos arquitetônicos para a acessibilidade, órteses e próteses, adequação postural, dentre outros.

Foram coletadas respostas que, de algum modo, mostram uma visão limitada acerca da compreensão dos professores quanto ao conceito de TA, onde alguns apresentaram respostas restritivas quanto aos ambientes em que pode ser utilizada, ao público que pode utilizá-la, bem como quanto ao que objetiva alcançar, como se pode verificar por meio dos excertos destacados a seguir:

São estratégias e alternativas de ensino dentro das SRM [...]. (P1).

São recursos que possibilitam a comunicação aos alunos que não possuem fala ou apresentam algum transtorno que impossibilitam uma linguagem, além de alunos com deficiência física que apresentam dificuldade de coordenação motora fina. (P3).

E um 'estrumento' que pode auxiliar na transmissão de fala (comunicação) verbal e não verbal. (P6).

Observa-se que o participante P1 limita o conceito de TA ao ambiente das SRM. Sabe-se que a Tecnologia Assistiva está inserida de diversos modos no cotidiano do indivíduo: na adaptação de veículos, como carros cujos comandos podem ser dados apenas com os membros superiores, em aparelhos eletrônicos, como os celulares com comandos de voz; em dispositivos ortóticos, como óculos, dentre outros.

Além disso, P1 restringiu a TA a área de ensino, o que a limita, como se pode observar nos exemplos listados acima. Logo este participante apresentou uma resposta duplamente limitada.

Já os participantes P3 e P6, destacaram apenas à área de comunicação, o que reflete em uma restrição do conceito e das áreas da TA, visto que, já que existem outras áreas, voltadas para outros objetivos e com públicos diversos.

A partir destas falas, pode-se apontar para a obtenção de um conceito limitado devido à vivência desses professores, já que as falas se restringem, frequentemente, ao ambiente escolar, à Comunicação Alternativa, aos alunos com deficiência e ao alcance do aprendizado.

Portanto, conclui-se que o ideal era a existência de formações contínuas, pois as realizadas por esta pesquisa conseguiram auxiliar os professores no sentido de ampliar visões acerca do 
processo de Inclusão Escolar, na otimização do processo de ensino-aprendizagem e na indicação de novas condutas profissionais, no entanto, nas respostas prevalecem as experiências cotidianas, como se pôde observar neste item.

Zanella e Tescarolo (2010) pontuam que a formação continuada é imprescindível para um educador devido auxiliar no desenvolvimento da eficácia de seu trabalho. Acrescentam que, durante a graduação, não receberam informações relacionadas aos elementos básicos da formação docente, com foco nas práticas em sala de aula.

Logo, o ideal seria a existência de um profissional permanente no cotidiano da escola, o qual teria o papel de assessorar os professores, bem como os próprios alunos. Pelosi (2005) considera o terapeuta ocupacional como um profissional fundamental para a elaboração de dispositivos de TA, já que possui competência exclusiva no sentido de enfatizar a função e a habilidade de realização das atividades cotidianas de casa, da escola, do trabalho ou, ainda, de lazer.

Quanto aos benefícios que ela pode trazer à pessoa com deficiência, observa-se restrição, visto que muitos relacionaram "pessoa" apenas a "aluno", o que resultou em tendência das respostas para áreas da Tecnologia Assistiva utilizadas primordialmente no ambiente escolar.

Favorece e facilita a aprendizagem dos conteúdos escolares e da vida diária. (P1).

Acessibilidade à comunicação, a atividades de vida diária. (P2).

Estimulação da comunicação, da aprendizagem da leitura, amplia o vocabulário. Promove a autonomia nas atividades de vida diária. (P3).

Os três participantes fazem alusão à utilização de recursos relacionados às Atividades de Vida Diária (AVD). P1 expõe em sua fala, ainda, a área de Atividades Instrumentais de Vida Diária (AIVD), através dos conteúdos escolares. Já o participante P3, também se refere às AIVD’s, mas em relação à leitura. P2 e P3 acrescentam a área referente à Comunicação.

Quando o ponto de discussão é o uso da TA para benefício do aluno com deficiência, há respostas que determinam um recurso a uma patologia específica, o que não é indicado. Inclusive, as formações ressaltaram frequentemente a importância da análise de cada caso e a infinita possibilidade de cada recurso, dependendo da criatividade de quem o gerencia.

A prancha de comunicação utilizada para organizar agenda para alunos com TEA, prancha de comunicação alternativa para o ensino aprendizagem para paralisados cerebral. (P3).

A tecnologia assistiva pode auxiliar alunos com ausência de fala por meio da comunicação alternativa e aumentativa e auxiliar alunos com dificuldade na preensão fina ou movimentos precisos através de adaptações como a tesoura adaptada e engrossador de lápis. (P8). 
O participante P3 relaciona os recursos listados especificamente a patologias e P8 associa as áreas da Tecnologia Assistiva a características específicas, o que não é adequado, visto que os recursos não se apresentam de modo imutável, com uma visão direcionada a apenas um aspecto, mas sim com possibilidades de adaptações e ressignificações, a depender da criatividade de quem o gerencia.

Rocha e Castiglioni (2005, p. 102) defendem que as definições dos recursos tecnológicos

[...] apontam, por diferentes caminhos para o paradigma da inclusão social da pessoa com deficiência. Essas abordagens inseridas em contextos diversos podem atingir ou não a meta proposta, ou seja, apenas o acesso aos equipamentos não garante a efetivação da finalidade proposta.

Portanto, para que determinado recurso atinja de fato o aluno, de modo a auxiliá-lo efetivamente e com qualidade, é necessário que exista uma análise aprofundada e individualizada a nível funcional, cognitivo, ambiental e social. Além disso, uma conduta interessante é, sempre que possível, solicitar auxílio do próprio aluno e da família deste para a escolha mais adequada.

Contudo, existiram também, respostas elaboradas de modo coerente com a ampla atuação da TA, em relação às áreas diversas em que pode se fazer presente, bem como com os conteúdos abordados durante as formações.

Essas respostas consideraram ambientes variados em que o indivíduo com deficiência pode se fazer presente, trazendo a noção da utilização da TA como elemento favorecedor do desenvolvimento, o bem estar, da autonomia e independência.

No que se refere aos conceitos de TA, observam-se como coerentes as seguintes respostas:

Recursos utilizados para facilitar e/ou proporcionar ao indivíduo condições de acessibilidade e qualidade de vida. (P2).

Toda e qualquer maneira (técnica), seja material como, psicológica, que se possa lançar mão, para auxiliar alguém a desenvolver seus potenciais, principalmente as pessoas com alguma deficiência. (P4).

São equipamentos, serviços, estratégias e práticas que auxiliam e/ou promovem ampliação e habilidades funcionais deficitárias. (P7).

O conceito de qualidade de vida é subjetivo e varia de autor para autor. Mas, de acordo com Vecchia (2005), o termo está relacionado a fatores como autoestima e bem estar pessoal, abarcando, portanto, capacidade funcional, nível socioeconômico, estado emocional, interação social, atividade intelectual, autocuidado, suporte familiar, valores culturais, éticos, religiosos, estilo de vida, satisfação com suas atividades e seu ambiente, bem como seu estado de equilíbrio biológico. 
Portanto, ao utilizar o termo "qualidade de vida", o sujeito P2 amplia a utilização dos recursos de TA de modo a abranger um número significativo de áreas, resultando no entendimento da ampla possibilidade de utilização destes, em diversos ambientes e contextos.

Outra visão de conceito é trazida nas considerações de P4, ao abordar elementos que indicam a absorção do conceito que inclui, enquanto Tecnologia Assistiva, recursos e serviços, visto que, apresenta a visão de recurso material e recursos humanos, como a "maneira psicológica" citada por ele. Esse conceito amplo também é explanado por P7, quando utiliza os termos "equipamentos", "serviços", "estratégias" e "práticas".

Quanto aos benefícios que a TA pode trazer a pessoa com deficiência, o conteúdo contemplado está relacionado a diversas áreas da vida do ser humano, de modo abrangente, permeando pelos aspectos sociais, psicológicos e físicos, na visão de um ser holístico. Como se pode observar na coleta a seguir:

Ampliação da percepção de mundo; Favorecimento de mobilidade e acessibilidade; Inclusão social. (P4).

A tecnologia assistiva pode auxiliar o deficiente a ter uma melhor interação com o seu meio social. (P6).

Independência; Qualidade de vida; Inclusão social. (P7).

Inclusão social; Independência nas atividades de vida diária; Melhora da autoestima e motivação. (P8).

As respostas de P4, P6, P7 e P8, exemplificadas acima, apresentam uma visão ampliada acerca das áreas em que a TA pode interferir positivamente de algum modo. A inclusão da TA na vida dos indivíduos pode ser visualizada como um fator promotor de saúde, já que saúde é sinônimo de qualidade de vida e bem estar físico, mental e social.

O conceito de saúde é subjetivo, de acordo com Brasil (2009, p.4), possui "relação com o desenvolvimento e expressa a associação entre qualidade de vida e saúde da população", sofrendo, portanto, influência pessoal, devido condições de vida adequadas de bens e serviços.

Portanto, a inserção de recursos e serviços de TA no cotidiano de pessoas com deficiência permite melhorias em aspectos sociais, devido interações com o meio e as pessoas; aspectos funcionais, onde é facilitada a função de elementos corporais; bem como os aspectos emocionais, relacionados à melhora da autoestima, da autoconfiança, possibilidade de autonomia e independência.

Quando indagados acerca dos benefícios da TA no ambiente escolar e o favorecimento desta para a Inclusão Escolar, os professores levaram em consideração benefícios psicomotores, cognitivos, emocionais e sociais, como pode se perceber nas seguintes afirmações: 
$\mathrm{Na}$ sala de recursos a TA pode ser usada diretamente para ampliar a comunicação do aluno, viabilizando sua aprendizagem. Assim como o processo de leitura, aprendizagem matemática e geral que auxiliaria a sala de aula. Outros benefícios seriam na psicomotricidade, percepção 'visomotora', coordenação motora fina e raciocínio lógico. (P5).

Sim. Uma vez que a tecnologia assistiva [...] se apropria de recursos e serviços que são utilizados para ampliar, manter ou até mesmo melhorar a capacidade funcional do aluno. A utilização dos recursos de acessibilidade vem contribuir para que o aluno possa participar e interagir efetivamente das atividades propostas nos diversos ambientes educacionais, assim como, auxilia o surgimento de laços afetivos entre os envolvidos. (P7).

Sim. Com o apoio da TA o aluno poderá mostrar através de outros recursos [...] respostas sobre o seu entendimento e/ou conhecimento, assim como a professora terá outros recursos para auxiliar seus alunos no favorecimento do processo ensino aprendizagem. (P10).

É possível perceber que os participantes se referem a TA como possibilidade de benefícios na área psicomotora, como a percepção viso motora e a coordenação motora fina; área cognitiva, ao citarem o raciocínio lógico, o aprendizado; área emocional, a partir da construção de laços afetivos sociais, do bem estar provocado pela autonomia; e na área social, através da interação efetiva e da comunicação.

Confirmando e reforçando as respostas trazidas neste item, Oliveira et al (2013) afirma que se faz imprescindível a utilização da Tecnologia Assistiva no contexto escolar para melhoria do processo ensino-aprendizagem, já possibilita a efetivação de uma maior integração entre o aluno e seu meio escolar, através de recursos de alta ou baixa tecnologia.

Esses recursos irão ser elementos facilitadores nesse processo de ensino-aprendizagem, podendo ser divididos de acordo com algumas áreas mais relevantes para o contexto escolar como a de recursos de acessibilidade ao computador, divididos em hardware e software, posicionamento postural, o qual irá atuar para manutenção, estabilização ou alcance de uma posição corporal adequada, e os recursos de Comunicação Alternativa Ampliada, que são os principais elementos facilitadores da interação.

Outra categoria construída foi "Benefícios da prática multiprofissional para a formação dos professores", a partir da qual se identificou que a formação possibilitou uma maior conscientização dos professores, no que cerne às suas próprias limitações no ensino do aluno com deficiência e em relação necessidade de ampliação e/ ou aprimoramento de suas práticas pedagógicas, no que se refere principalmente na confecção de recursos de Tecnologia Assistiva, como se pode perceber nas seguintes falas:

Pude perceber o quanto minha prática pedagógica está aquém do esperado. Até porque as demandas são variadas e todos os dias surgem informações novas a serem aprendidas. Esse dois sábados reavivaram em mim, a necessidade de aprender cada vez mais [...]. (P7). 
Foi muito importante, pois observei que é possível confeccionar muitos recursos com materiais de baixo custo e surtir bons resultados com os alunos. (P9).

[...] foi possível constatar que podemos com recursos baratos e alternativos estar possibilitando ao aluno, condições para que ele aprenda [...]. (P2).

Essas percepções dos professores, em relação às limitações que possuem, concordam com que fora defendido por Martins (2006), ao afirmar que, através de estudos realizados sobre atitudes de professores frente à inserção de crianças com deficiência, fora evidenciado que muitos destes não se consideram preparados ou aptos para os desafios impostos pela proposta da Educação Inclusiva, refletindo assim, a necessidade de formação continuada nessa área.

Observa-se que P2 ressalta o distanciamento de sua prática pedagógica em relação ao que lhe é requerido. Esta mesma inquietação foi encontrada em professores atuantes nas SRM, conforme evidenciado em um estudo realizado por Galvão (2012) o qual ressaltou que uma queixa recorrente destes professores motivo de tal inquietação, referia-se exatamente a falta de um maior aprofundamento em sua formação. Nesse sentido pode-se constatar que a realidade apresentada por Galvão em 2012, é também a realidade de alguns professores da SRM, do município de Belém.

É interessante notar que P2 justifica sua dificuldade devido a variedade de demandas com a qual se depara e com a dificuldade de lidar com o acelerado processo de atualizações e aprendizagens de novas estratégias de ensino. Este achado aponta também para a falta de preparação destes profissionais ou ainda para a necessidade de uma equipe composta por outros profissionais para atuar junto a este professore nesse espaço.

Por outro lado, esses dados, sinalizam que a formação proposta implicou na sensibilização dos professores em relação à possível limitação de suas práticas pedagógicas e sobre a necessidade de aprimoramento destas. Fator que se constitui como importante, visto que poderá levar este profissional a ser um agente ativo em seu processo de formação.

Acerca desta temática, Cavalcante e Lima (s.d.) discorrem que para a efetivação do processo de Inclusão Escolar, é necessário também que os professores exercitem constantemente sua reflexão e questionem suas práticas e consequentemente busquem caminhos pedagógicos de Inclusão.

Pode-se afirmar, portanto, que a ação desenvolvida contribuiu positivamente para a formação destes professores, partindo da perspectiva de que a formação constitui-se num processo contínuo que vai muito além da realização de cursos. É um processo constante, no qual o professor necessita de auxílio para refletir sobre sua prática em sala de aula (SANDALLA apud IDE; YMAMOTO; SILVA, 2011). 
Constata-se ainda que o terapeuta ocupacional também contribue no fomento de reflexões nesse professor, viabilizando assim, a reconfiguração e a ressignificação de suas práticas pedagógicas.

Outro importante aspecto observado pelos professores após a formação refere-se à construção de recurso de TA e sua utilização como uma possibilidade de melhorar o processo de ensino aprendizagem dos alunos com deficiência. Reforçando esta ideia, Rocha e Liberato (2012) afirmam que o uso da TA, possibilita ao aluno com deficiência a acessibilidade, e favorece o seu processo de aprendizagem e o desenvolvimento de diferentes habilidades.

P9 e P7 expressaram a conscientização, adquirida especificamente em relação à construção de recursos diversos e de baixo custo que podem ser utilizados em suas práticas e otimizar o processo de aprendizagem desse aluno.

Sabe-se que uma das habilidades ou competências requeridas dos profissionais da SRM, diz respeito elaboração de recursos pedagógicos que favoreçam o desenvolvimento desse aluno. Considerando isso, pode-se afirmar que estes professores não estão correspondendo ao que lhe é requerido pela legislação nesse sentido.

Sobre a importância dessa prática, Galvão Filho e Miranda (2012) constataram em seus estudos que, a disponibilização de recursos e adaptações bastante simples e artesanais, construídos às vezes pelos próprios professores, podem fazer a diferença, para determinados alunos com deficiência, entre poder ou não estudar e aprender junto com seus colegas.

Nesse sentido, é interessante ressaltar ainda que atualmente existe um número muito expressivo de possibilidades, de recursos simples e de baixo custo, que podem e devem ser disponibilizados nas salas de aula inclusivas, conforme as necessidades específicas de cada aluno com necessidades educacionais especiais (GALVÃO, 2011).

Portanto, o diálogo entre Terapeutas Ocupacionais e professores possibilitou esclarecimentos fundamentais sobre TA e a sensibilização sobre a importância da construção desses recursos, o que pode refletir diretamente na otimização da prática pedagógica dos professores da Educação Inclusiva.

Nesse sentido é importante ressaltar que vários estudos têm evidenciado a significativa e diferenciada contribuição do terapeuta ocupacional na formação dos professores no que concerne à indicação e efetivação dos recursos e serviços de TA (LUIZ; ROCHA; ZULIAN 2003).

Nesta categoria, pode-se perceber ainda que a equipe profissional é concebida pelos professores como fundamental e de extrema importância para a efetivação do processo de Inclusão Escolar, como é possível visualizar nas seguintes respostas: 
É fundamental, para que tenhamos um olhar da totalidade perante nosso estudante. Acontece também que a equipe multiprofissional amplia as possibilidades de avaliação desse aluno, nos direcionando melhor dentro de sala de aula e é claro para a vivência (melhoria) desse estudante. (P1).

[...] a avaliação deve ser realizada com uma equipe multifuncional possibilitando o uma observação mais ampla das potencialidades e dificuldades do aluno com deficiência [...]. (P3).

[...] funciona como base para a confecção de materiais que poderão auxiliar por exemplo um aluno com algum tipo de paralisia. (P9).

De extrema importância na colaboração do desenvolvimento do aluno. (P10).

Os professores P1 e P3 consideram a equipe como fundamental, por possibilitar uma avaliação mais completa do aluno, ou seja, a identificação tanto das limitações como das potencialidades, além do olhar holístico sobre este aluno.

Esta concepção dos professores sobre a equipe multiprofissional foi a mesma evidenciada nos estudos de Cavalcante e Lima (s/d) onde os professores destacaram fundamental e importante participação de outros profissionais, para a inclusão de alunos com deficiência na escola regular.

É importante observar que essas colocações dos professores podem sinalizar possíveis limitações em sua atuação junto ao aluno com deficiência. Segundo Cavalcante e Lima (s.d.), é requerido destes professores a capacidade de avaliar os alunos com deficiência, identificando suas reais necessidades e principalmente suas potencialidades.

Esta etapa constitui-se em uma etapa crucial que vai repercutir em todo o processo de aprendizagem deste aluno, pois somente a partir desta é que poderão ser feitas as adaptações devidas nos conteúdos do programa de ensino, na utilização de tecnologias, na introdução de metodologias pedagógicas efetivas.

Portanto, deve-se atentar não somente para a limitação da atuação desses profissionais, mas também para a importância e necessidade legítima de uma equipe que forneça um suporte efetivo para este professor.

Sobre a necessidade da equipe multiprofissional para a efetivação do processo de Inclusão Escolar, de acordo com Rodrigues (2006), não se pode pensar que o professor será capaz de assumir e responder a tudo e a que todas as profissões se propõem desenvolver. Se a escola regular quiser ser capaz de responder com competência e rigor à diversidade de todos os seus alunos necessitará de uma organização diferenciada de aprendizagem devendo contar com uma equipe composta por diversos profissionais (trabalhadores sociais, psicólogos, terapeutas, etc.).

Além disso, as respostas dos professores apontaram a troca de conhecimentos como elemento favorecedor para a elaboração de diferentes estratégias de ensino e a confecção de recursos de Tecnologia Assistiva para a potencialização das habilidades dos alunos. 
Ainda sobre o papel da equipe multiprofissional, Lima (1999) defende que é importante que escola conte com outros profissionais que possam contribuir com os professores diante das demandas que vierem a surgir no contexto escolar.

A última categoria foi intitulada "Terapia Ocupacional x Inclusão Escolar", a qual analisa o conhecimento, as percepções e as concepções dos sujeitos da pesquisa em relação à atuação do profissional terapeuta ocupacional no contexto da Inclusão Escolar.

O primeiro eixo refere-se ao conhecimento dos professores em relação ao profissional de Terapia Ocupacional atuante no processo de Inclusão Escolar antes da realização da formação. Neste eixo, busca-se identificar conhecimento que os professores tinham sobre a inserção do terapeuta ocupacional no campo educacional antes da formação realizada. Dos sujeitos da pesquisa, cinco professores não conheciam o terapeuta ocupacional como profissional atuante na Inclusão Escolar. Como se pode observar a seguir:

Não. Sei que a maioria dos meus alunos tem acompanhamento de T.O., mas não sei as dificuldades e benefícios do trabalho desenvolvido. (P5).

Não. Inclusive falei à professora Mariane que este passo dado é muito importante para nós profissionais da educação, a aproximação entre a educação e a saúde. Sinceramente, desconhecia o quanto o terapeuta ocupacional pode auxiliar o trabalho de nós, professores. (P7).

Não, somente como profissional da área de saúde. (P10).

Em relação ao não conhecimento do terapeuta ocupacional no contexto da escolar regular, esses achados, assemelham-se com os resultados da pesquisa de Cunha et al (2008) que realizou um estudo, cujo objetivo principal foi identificar as concepções dos professores de um município de São Paulo sobre a atuação do terapeuta ocupacional na educação.

A partir deste, evidenciou-se que não havia conhecimento do papel do terapeuta ocupacional junto à escola regular, contudo, os professores julgavam importante a parceria entre saúde e educação.

Pode-se inferir ainda que o não conhecimento do profissional de Terapia Ocupacional deve-se também ao que afirma Ide, Yamamoto e Silva (2011), quando destacam que no Brasil a atuação da Terapia Ocupacional na escola regular é recente, tanto no que se refere à prática profissional quanto à pesquisa.

Sendo assim, esse resultado pode ser reflexo da ausência de terapeutas ocupacionais contratados na área da educação, visto que este profissional ainda não esta inserido efetivamente nessa área no município de Belém. 
Nesse aspecto, é importante salientar que a proposta da formação contribuiu para a divulgação do trabalho desses profissionais, e foi de extrema importância o estabelecimento da parceria entre terapeutas ocupacionais e professores, pois possibilitou a discussão e elaboração conjunta de possíveis estratégias que poderiam ser utilizadas junto às crianças com deficiência.

Dentre os que referiram conhecer o profissional de Terapia Ocupacional, estes alegaram não compreender, antes da formação proposta, as diversas possibilidades de atuação Terapêutica Ocupacional nesse processo, apresentando desta forma, um entendimento limitado acerca da atuação deste profissional, através das seguintes falas:

Sim, mas de forma superficial, hoje conheço um pouco mais e acredito que este 'profissional' possui condições de contribuir em vários aspectos. (P2).

Sim, porém não imaginava que não estariam inseridos no quadro da equipe multiprofissional e nem sabia que eram os responsáveis por pensar e confeccionar os recursos. (P9).

Sim, porém não dimensionava a importância da T.O. no processo de Inclusão Escolar do aluno com deficiência. (P6).

Como analisado anteriormente, esse conhecimento limitado em relação a prática Terapêutica Ocupacional nesse contexto, pode ser reflexo da recente pouca incidência da inserção destes profissionais no campo educacional.

Além disso, Ide, Yamamoto e Silva (2011) ressaltam ainda que é essencial que haja a consolidação da atuação do terapeuta ocupacional na educação regular, estabelecendo efetiva interface entre as áreas da Saúde e da Educação, tão necessária para os processos de desenvolvimento e de inclusão da criança com deficiência.

No eixo referente às concepções sobre a atuação do terapeuta ocupacional no processo de Inclusão Escolar, buscou-se evidenciar como os professores concebem a atuação do terapeuta ocupacional no processo de Inclusão Escolar, após a formação proposta. Através das respostas, evidenciou-se a importância deste profissional no assessoramento dos professores.

Neste aspecto, foi bastante ressaltado a contribuição no que cerne a formação dos professores em relação à utilização dos recursos disponíveis salas, na própria construção de recursos de Tecnologia Assistiva, na avaliação da funcionalidade e na indicação do recurso, que poderá ser utilizado com aluno. De maneira geral, contribuiu-se com o fornecimento de orientações que podem favorecer o desenvolvimento e a inclusão do aluno no contex to escolar.

Além disso, os professores citaram a atuação do terapeuta ocupacional junto às famílias dos alunos ainda como um profissional com que é possível compartilhar as "angustias". Tais aspetos podem ser visualizados através das seguintes salas. 
Um parceiro extremamente atuante e de grande valor. Um profissional que pode estar assessorando os professores das salas de recursos com suas técnicas, auxiliando nos materiais que na nossa sala existem no entanto, em muitas das vezes não sabemos como utilizar. E até mesmo na construção de muitos desses materiais, de estar participando junto com o professor (a) SRM, de encontros com 'terapias' voltadas para orientações dessa família com foco no estudante. As possibilidades de parcerias são muitas e fundamentais. (P1).

É importante que este profissional atue na área da educação possibilitando leituras e observações que contribuem para o desenvolvimento das potencialidades da criança e adolescente incluso no ensino regular. A contribuição na avaliação e funcionalidade do recurso a ser indicado para o aluno contribui com o processo de desenvolvimento do cognitivo e da autonomia de vida diária. (P3).

Sim. Agora tenho certeza que sim. Falando de minha experiência nesse curso, vocês trouxeram para mim a necessidade de olhar com atenção redobrada para os recursos utilizados. Todos os profissionais envolvidos nessa formação falaram a mesma linguagem, destaco a sensibilidade na decisão do recurso a ser utilizado com o aluno, em que este decidirá qual o melhor recurso a ser usado pelo próprio. (P7).

A partir de tais comentários, pode-se verificar que o trabalho realizado pela equipe, as palestras ministradas, os diálogos entre professores e Terapeutas Ocupacionais, pode ampliar significativamente o conhecimento desses profissionais sobre as possibilidades de atuação terapêutica ocupacional no contexto da escola regular, na perspectiva da Educação Inclusiva.

Nesse contexto, segundo Pelosi (2006), o terapeuta ocupacional é um profissional qualificado para trabalhar como facilitador do processo de Inclusão, pois é dotado da capacidade de reconhecer a diversidade em diferentes áreas e, principalmente, a possibilidade de favorecer a funcionalidade das potencialidades de cada indivíduo.

É importante notar que P1 ressaltou a importância do terapeuta ocupacional no assessoramento do professor. Sobre isso, Rocha, Luiz e Zulian (2003) corroboram com essa ideia ao apontarem, de maneira geral, que o alvo da Terapia Ocupacional nesse contexto, é fortalecer a potência de ação dos professores, através da criação de soluções para os impasses que podem vir a surgir a partir do próprio grupo e de sua realidade.

Tanto P1 como P3 e P7, ressaltaram a contribuição do terapeuta ocupacional em relação à utilização dos recursos de tecnologia assistiva. Pode-se inferir que este aspecto fora bastante enfatizado, devido a formação proporcionada abordar esta temática.

Corroborando com as ideias apresentadas pelos professores, em relação ao terapeuta ocupacional e a tecnologia assistiva no contexto escolar, Pelosi (2006) e Rocha, Luiz e Zulian (2003) ressaltam que o terapeuta ocupacional poderá confeccionar e/ou indicar utilização de recursos e também ensinar educadores e familiares a confeccionarem os recursos de acordo com as necessidades encontradas e, além disso, fornecer orientações sobre os limites e alcance desses recursos na relação do aluno com o meio e no processo de aprendizagem. 
Além disso, um estudo realizado por Galvão (2009), junto a professores das Salas de Recursos Multifuncionais, evidenciou que estes profissionais dispunham, neste espaço, de diversificados recursos de tecnologia assistiva, porém estes não eram utilizados, devido a não apropriação dos mesmos.

Sobre isso é muito válido enfatizar que o terapeuta ocupacional é um profissional habilitado também para possibilitar a apropriação destes recursos, visto que em sua prática, lida com tais instrumentos desde o nascimento da profissão.

Sobre o que fora destacado por P9, um estudo realizado por Della Barba (2009) aponta as possibilidades de atuação da Terapia Ocupacional no que se refere ao desenvolvimento de atividades de suporte junto aos professores e equipe escolar.

Este autor, afirma que o suporte oferecido pode melhorar as sensações de frustração e impotência diante das dificuldades apresentadas em lidar com as particularidades de cada deficiência, pois quando as dificuldades são compartilhadas, os professores deixam de sentirem-se sozinhos no processo de Inclusão.

Outro aspecto ressaltado por P1 foi sobre a possibilidade de atuação junto à família dos alunos com deficiência. Sobre isso, Bartalotti e De Carlo (2001) destacam que terapeuta ocupacional pode atuar junto às famílias dos alunos com necessidades educacionais especiais, objetivando construir com a família um meio social que permita a este sujeito viver em situações ricas em experiências e oportunidades.

Além disso, segundo Ide, Ymamoto e Silva (2011), o terapeuta ocupacional pode favorecer um diálogo fundamental entre a família, considerada como importante colaboradora no processo de Inclusão, por possuir um maior conhecimento acerca das habilidades da criança com deficiência- e a escola, objetivando otimizar o desenvolvimento do aluno com deficiência.

Portanto, pode-se verificar que a formação realizada contribuiu significativamente para ampliar o conhecimento dos professores em relação à contribuição do terapeuta ocupacional no processo de Inclusão Escolar, principalmente a sua contribuição no que se refere à utilização da Tecnologia Assistiva, visto que a formação proposta dava ênfase para esse aspecto.

Embora outras possibilidades de atuação do terapeuta ocupacional, tenham sido apontadas pelos professores, como por exemplo, sua atuação junto à família do aluno e junto ao próprio professore no sentido de lhe fornecer um suporte que não esteja relacionado a TA- sendo estas concepções adquiridas a partir do que fora discutido com estes durante as formações- percebe-se que a concepção dos professores sobre os Terapeutas ocupacionais ainda não abrange todas as formas de como este profissional possa contribuir no processo de Inclusão Escolar. 
Sendo assim, é necessário dar continuidade ao desenvolvimento de ações que viabilizem o reconhecimento dos Terapeutas Ocupacionais no contexto escolar.

\section{Considerações finais}

Este estudo buscou evidenciar possíveis contribuições da Terapia Ocupacional para a atuação de professores do Atendimento Educacional Especializado (AEE), no que concerne à utilização de Tecnologia Assistiva, e consequentemente favorecer o processo de Inclusão Escolar.

Para o alcance dos resultados, fez-se necessário modificar aspectos metodológicos devido à apresentação de percalços ao longo da execução da pesquisa, tais como, dificuldades no processo inicial de coleta de dados, a indisponibilidade de horário dos professores em participar da segunda etapa da pesquisa, burocracias institucionais e o número total de sujeitos que aceitaram participar do processo.

Reitera-se que as alterações metodológicas não comprometeram o alcance dos objetivos pré-estabelecidos. Para a obtenção dos resultados, levaram-se em consideração elementos peculiares a cada indivíduo e elementos comuns ao grupo.

Pode-se constatar que estes professores possuem dificuldades de lidar com as diversas demandas que se apresentam em seu cotidiano junto aos alunos nas SRM. Dentre estas, pode-se identificar dificuldades de avaliação das potencialidades deste aluno e de utilização de metodologias condizentes com a necessidade apresentada. Além disso, ressaltou-se a dificuldade de apropriação de alguns recursos de Tecnologia Assistiva devido não conhecerem a funcionalidade destes.

Ao analisar os resultados da formação proposta, evidenciou-se quão ampla e diversificada pode ser a contribuição da Terapia Ocupacional no campo educacional, tanto no que se refere à instrumentalização dos professores na utilização da Tecnologia Assistiva, como em abordagens junto ao aluno, à família e a toda comunidade escolar. A formação realizada não só possibilitou a aquisição de conhecimentos no que se refere aos recursos de Tecnologia Assistiva, bem como contribuiu para suscitar reflexões importantes e necessárias para o aprimoramento das práticas pedagógicas dos sujeitos de pesquisa.

Portanto, ressalta-se que o terapeuta ocupacional constitui-se em um profissional que reúne conhecimentos, habilidades e competências para contribuir diferenciadamente e significativamente na potencialização tanto dos alunos como dos professores, e consequentemente na efetivação do processo de Inclusão Escolar.

Este profissional domina a análise das atividades humanas, desde suas áreas até seus componentes, ou seja, dos aspectos mais abrangentes, aos mais específicos. Logo, o terapeuta 
ocupacional é o profissional mais indicado para a confecção e indicação do recurso de Tecnologia Assistiva junto ao indivíduo com deficiência, já que este profissional está apto a avaliar as possibilidades de otimização dos aspectos funcionais, bem como relacionais/sociais.

O ideal seria ter esse profissional permanentemente nas escolas, trabalhando em auxílio aos professores, seja na sala de recursos multifuncionais diretamente com o aluno, no acompanhamento da família, e até mesmo com os alunos da escola como um todo, visto que cada ser é único e subjetivo, onde, dependendo de suas preferencias e da metodologia utilizada, pode apresentar maior ou menor aprendizagem.

Contudo, seria incoerente negar que há uma série de barreiras a serem transpostas para que a proposta da Educação Inclusiva se consolide da maneira desejada. Uma delas é a barreira que alguns profissionais possuem em relação às demais profissões. Algumas pessoas tem resistência em exercer o trabalho integrado, como uma equipe transdisciplinar, visto que, têm receio de perderem espaço de sua profissão com o trabalho do outro.

No entanto, existem aqueles são mais receptivos a novos conhecimentos, que valorizam a qualidade de seu trabalho. Esses indivíduos se beneficiam consideravelmente com a troca de saberes. É válido considerar também que os maiores beneficiados dessa interação multiprofissional são os sujeitos usuários do serviço.

Nesse sentido não se pode deixar de mencionar a singular importância de uma equipe interdisciplinar que seja capaz de articular saberes, aprimorando a qualidade de atenção oferecida aos alunos, contribuindo para o desenvolvimento desses e consequentemente para a transposição dos percalços encontrados diante da proposta da Inclusão.

Nem de longe, buscou-se esgotar o assunto, mas objetivou-se, através dos resultados do estudo, contribuir e corroborar com as pesquisas existentes sobre a temática e servir de embasamento para estudos sobre o tema da Inclusão Escolar e Tecnologia Assistiva, bem como aumentar arcabouço teórico que relaciona a prática terapêutica ocupacional a este tema. Buscou-se ainda suscitar inquietações e ideias para pesquisas futuras.

A dificuldade de estabelecer um maior contato com a maioria dos professores foi um fator interessante nessa pesquisa. De que forma trocar saberes se existe uma quantidade significativa de profissionais que não se dispõem? Quando comparamos o número de professores convidados para participar da pesquisa (cerca de 100 professores, se pensarmos que cada escola possa ter três profissionais) e o número de indivíduos que se dispuseram a participar (apenas 13), pode-se visualizar o quanto a aderência foi reduzida. 
Tal situação ocorreu em um contexto onde os dias das formações foram pensados previamente, readequados ao calendário da maioria dos professores; disponibilizou-se certificado para aqueles que participaram das formações; ocorreu uma oficina, com momentos práticos de confecção de materiais, sem que os professores precisassem financiar nada. E mesmo com toda essa flexibilidade e disposição das pesquisadoras, a maioria não participou.

No entanto, é válido pontuar que a experiência foi incrível, pois foi possível observar nas falas dos participantes o quanto eles conseguiram absorver conceitos, ideias para a atuação profissional e o quanto ficaram satisfeitos com as explanações dos módulos. Pode-se dizer que foi plantada uma semente, onde se espera que ela seja cultivada, através do compartilhamento das informações recebidas com outros colegas de profissão, bem como da aplicação com os alunos, resultando na efetivação do processo de Inclusão.

Ressalta-se ainda que a pesquisa contribuiu significativamente na formação acadêmica das pesquisadoras, constituindo-se em uma ferramenta que aprimorou o conhecimento destas em relação ao tema em questão. Através da experiência pode-se apropriar mais da realidade vivenciada no campo educacional, compreender com maior propriedade as dificuldades que perpassam esse contexto sendo que esta compreensão constitui-se em um fator fundamental para suscitar reflexões e repensar práticas efetivas para processo de Inclusão Escolar.

O desenvolvimento desta pesquisa constituiu-se em um processo muito gratificante, pois possibilitou trocas de saberes, onde o foco principal é o bem estar dos usuários das salas de recursos multifuncionais e, a partir dessa troca, proporcionar a esses indivíduos uma melhora em sua qualidade de vida.

\section{Referências}

AOTA - American Occupational Therapy Association (2008). Occupational therapy practice framework: Domain and process. (2nd ed.). American Journal of Occupational Therapy, 62, $625-683$.

BARDIN, Laurence. Análise do conteúdo. Lisboa: Edições 70, 2014. 288 p.

BARTALOTTI, Celina Camargo. DE CARLO, Marysia M. R. Do Prado. Terapia Ocupacional e os processos socioeducacionais. In : BARTALOTTI, Celina Camargo. DE CARLO, Marysia M. R. Do Prado (Org.) Terapia Ocupacional no Brasil- Fundamentos e Perspectivas. São Paulo: Plexus Editora, 2001. 
BERSCH, R; SCHIRMER, C. Tecnologia assistiva no processo educacional. In: BRASIL, Ministério da Educação. Ensaios Pedagógicos: Construindo Escolas Inclusivas. p. 87 - 92. Brasília, 2005.

BRASIL: Ministério da Educação. Secretaria de Educação Especial. Política Nacional de Educação Especial na perspectiva da Educação Inclusiva. Brasília: MEC/SEESP, 2007.

BRASIL. Ministério da Saúde. Resolução CNS N 466/2012. Diário Oficial da União, Brasília, 13 de junho de 2013. Seção 1, p.59. Disponível em: <http://conselho.saude.gov.br/resolucoes/2012/Reso466.pdf $>$. Acesso em 15/06/2014.

BRASIL. Ministério da Saúde - Agência Nacional de Vigilância Sanitária (ANVISA). A ANVISA na redução à exposição involuntária à fumaça do tabaco. Brasília, 2009.

BRASIL. Portaria Normativa n. 13, de 24 de abril de 2007. Dispõe sobre a criação do "Programa de Implantação de Salas de Recursos Multifuncionais". Documento elaborado por Fernando Haddad. Brasília: Ministério da Educação, 2007.

CAVAlCANTE, Tícia Cassianny Ferro; LIMA, Helidiane Souza. A Formação Continuada do professor para Educação Inclusiva na Rede Municipal de Recife. Disponível em: www.ufpe.br/.../a\%20formao\%20continuada\%20do\%20professor\%. Acesso em: 01/06/2014

CUNHA, V. D. S.; SILVA, A. C. A.; SILVA, J. A.; POKER, R. B. Concepção de Professores sobre a Atuação da Terapia Ocupacional nas Escolas da Rede Pública Municipal de Marília. In: CONGRESSO BRASILEIRO DE EDUCAÇÃO ESPECIAL, 3., 2008, São Carlos. Anais... São Carlos, 2008.

DELLA BARBA, P.C.S. Consultoria colaborativa na Inclusão Escolar de crianças com transtornos do desenvolvimento: proposta de atuação da Terapia Ocupacional. In: CONGRESSO BRASILEIRO DE TERAPIA OCUPACIONAL, 11., 2009, Fortaleza. Anais do Congresso Brasileiro de Terapia Ocupacional. Fortaleza: Associação Brasileira dos Terapeutas Ocupacionais, 2009.

FRIAS, E.; MENEZES, M. Inclusão escolar do aluno com necessidades educacionais especiais: contribuições ao professor do Ensino Regular. Disponível em: <http://www.diaadiaeducacao.pr.gov.br/portals/pde/arquivos/1462-8.pdf $>$. Acesso em $<21 / 05 / 2013>$.

GALVÃO FILHO, T. A.; MIRANDA, T. G. Tecnologia Assistiva e salas de recursos: análise crítica de um modelo. In: GALVÃO FILHO, T. A. MIRANDA, T. G. (Orgs.). O professor e a Educação Inclusiva: formação, práticas e lugares. Salvador: Editora da Universidade Federal da Bahia - Ed. UFBA, 2012, p. 247-266.

GALVÃO FILHO, T. Favorecendo práticas pedagógicas inclusivas por meio da Tecnologia Assistiva. In: NUNES, L. R. O. P.; PELOSI, M. B.; WALTER, C. C. F. (Orgs.). Compartilhando experiências: ampliando a comunicação alternativa. Marília: ABPEE, p.71-82, 2011.

GALVÃO FILHO, T. Tecnologia Assistiva para uma Escola Inclusiva: apropriação, demandas e perspectivas. Tese (Doutorado em Educação) - Faculdade de Educação, Universidade Federal da Bahia, Salvador, 2009. 
IDE, Mariana Graziella; YAMAMOTO Beatriz Tieko; SILVA, Carla Cilene Baptista da. Identificando possibilidades de atuação da Terapia Ocupacional na Inclusão Escolar. Cad. Ter .Ocup. UFSCar, São Carlos, v. 19, n. 3, p. 323-332, 2011.

LIMA, Suzana. Atuação de uma equipe multi e interdisciplinar em educação especial. Anais do III Congresso Brasileiro Sobre Educação Especial, maio, 1999, pp.279-82.

MARTINS, L. A. R. Formação de professores numa perspectiva inclusiva: algumas constatações. In: MANZINI, E. J. (Org.) Inclusão e Acessibilidade. Marília: ABPEE, 2006. p. 17-27.

OLIVEIRA, A. I.; OLIVEIRA, F. H. F.; SOUZA, G. S; PANTOJA, J. P.; CARMO, R. F.; CASTILHO, S. H. S. Levantamento das necessidades de recursos de Tecnologia Assistiva nas escolas inclusivas municipais de Belém - PA. In: OLIVEIRA, A. I. ZAPAROLI, D. A.; ASSIS, G. J. A.; PINHEIRO, M. A. Desenvolvimento Humano: contribuições para a aprendizagem e a inclusão social. Belém: Eduepa, 2013.

OLIVEIRA, Ana Irene Alves; SILVA, Rafael Luiz Morais; ZAPAROLI, Danielle Alves (Orgs.). Inovação tecnológica e inclusão social. Belém: EDUEPA, 2011.

PELOSI, M. B. O papel do terapeuta ocupacional na Tecnologia Assistiva. Cadernos de Terapia Ocupacional da UFSCAR, v. 13, n.1, 2005.

PELOSI, M. Por uma escola que ensine e não apenas escolha recursos e estratégias para a Inclusão Escolar. In: MANZINI, E. (Org). Inclusão e acessibilidade. Marilia: ABPEE, 2006. p. 121-132.

ROCHA, A; LIBERATO, D. Atuação do terapeuta ocupacional no contexto escolar: o uso da tecnologia assistiva para o aluno com paralisia cerebral na educação infantil. Rev. Ter. Ocup. Univ. São Paulo, v. 23, n. 3, p. 263-73, set./dez.2012.

ROCHA, E. F.; CASTIGLIONI, M. C. Reflexões sobre recursos. Rev. Ter. Ocup. Univ. São Paulo, v. 16, n.3, p.97-104, set./dez., 2005.

ROCHA, E. F.; LUIZ, A.; ZULIAN, M. A. R. Reflexões sobre as possíveis contribuições da Terapia Ocupacional nos processos de Inclusão Escolar. Rev. Ter. Ocup. Univ. São Paulo, v. 14, n. 2, p. 72-8, maio/ago. 2003.

RODRIGUES, David. Dez idéias (mal) feitas sobre a Educação Inclusiva. In: RODRIGUES, David (Org.). Inclusão e Educação: Doze Olhares Sobre a Educação Inclusiva. São Paulo: Summus, 2006.

TEIXEIRA, Elizabeth. As três metodologias: acadêmica, da ciência e da pesquisa. 6. ed. Petrópoles, RJ: Vozes,2009. 203p.

VECCHIA, Roberta Dalla; RUIZ, Tania; BOCCHI, Silvia Cristina Mangini; CORRENTE, José Eduardo. Qualidade de vida na terceira idade: um conceito subjetivo. Rev. bras. epidemiol. [online]. 2005, vol.8, n.3, pp. 246-252. Disponível em: $<$ http://www.scielo.br/scielo.php?script=sci_arttext\&pid=S1415-790X2005000300006>. Acesso em 21 jun. 2014.

ZANELLA, Camila; TESCAROLO, Ricardo. A prática dos professores recém-formados e a sua formação continuada. In: Simpósio Nacional de Educação, 2; Semana de Pedagogia, 21, Cascavel, 
2010. Anais do II Simpósio Nacional de Educação / XXI Semana de Pedagogia, Cascavel: UNIOESTE, 2010.

Recebido em: 07.11.2014 Aceito em: 18.11.2015 